\title{
Regulatory Peptides from Chromogranin A and Secretogranin II
}

\author{
Karen B. Helle
}

Received: 7 June 2010/Accepted: 23 July 2010/Published online: 19 November 2010

(c) The Author(s) 2010. This article is published with open access at Springerlink.com

\begin{abstract}
This commentary is focusing on novel aspects on the secreted $\mathrm{CgA}$ - and SgII-derived peptides, vasostatinI (bovine and human $\mathrm{CgA}_{1-76}$, VS-I), WE-14 ( $\left.\mathrm{CgA}_{316-329}\right)$, catestatin (bovine $\mathrm{CgA}_{344-366}$, human $\mathrm{CgA}_{352-372}$, Cts) and the SgII-derived secretoneurin $\left(\mathrm{SgII}_{180-204}\right)$ as significant regulators of inflammatory reactions.
\end{abstract}

Keywords Vascular endothelium · Transendothelial transport · PMNs · Chemotaxis · Angiogenesis

The regulatory roles of granins in sorting and secretion still dominate as topics at the international symposia on chromaffin cell biology (ISCCB), as indeed evident from the 15th ISCCB in Merida, Mexico, November 12-16, 2010. In this article, only 2 out of 12 sessions were devoted to effects of secreted granins such as Chromogranin A ( $\mathrm{CgA})$ and Secretogranin II (SgII). Consequently, among the nine contributions dealing with granins in the proceedings of this meeting, there is only one review dealing with the modulating effects of $\mathrm{CgA}$ and its $\mathrm{N}$-terminal peptide vasostatin-I (VS-I) on growth and vascularization of neuroendocrine tumors (Corti 2010). In addition, there is one original contribution concerning cardiovascular aspects of the CgA peptide catestatin (Penna et al. 2010). Thus, despite more than four decades since the first documented

This is a commentary to articles doi:10.1007/s10571-010-9564-2, 10.1007/s10571-010-9584-y, 10.1007/s10571-010-9585-x, $10.1007 / \mathrm{s} 10571-010-9587-8,10.1007 / \mathrm{s} 10571-010-9595-8$, 10.1007/s10571-010-9598-5.

K. B. Helle $(\bowtie)$

Department of Biomedicine, University of Bergen,

Jonas Lies vei 91, 5009 Bergen, Norway

e-mail: karen.helle@biomed.uib.no co-secretion of the water-soluble, granule-specific protein (later to be named $\mathrm{CgA}$ ) and catecholamines by exocytosis in vitro (Banks and Helle 1965) and in vivo (Blaschko et al. 1967), aspects of the granins in amine and peptide storage and release have remained in focus at the expense of the extracellular impact of the granin cargo as prohormones for regulatory peptides. Hence, it seems timely to balance the overall picture with a commentary focusing on novel aspects on VS-I (bovine and human $\mathrm{CgA}_{1-76}$, VS-I) and catestatin (bovine $\mathrm{CgA}_{344-366}$, human $\mathrm{CgA}_{352-372}$, Cts) and the SgII-derived secretoneurin $\left(\mathrm{SgII}_{180-204}\right)$ as significant players in inflammatory processes (Helle 2010a, b).

The prohormone concept (Eiden 1987) implies that rather than being biologically inert "garbage" from the diffuse neuroendocrine system, the granins may serve as precursors of smaller peptides that, once released into the extracellular space, may serve some autocrine, paracrine, and/or endocrine function. The experimental support for this concept is escalating, notably for $\mathrm{CgA}$ and SgII. A wide range of processes, such as innate immunity, inflammatory and autoimmune reactions, cardiovascular modulations and several homeostatic regulations are affected (Metz-Boutigue et al. 1998; Fischer-Colbrie et al. 2005; Helle et al. 2007; Helle 2009, 2010a, b; Mahapatra 2008). Notably CgA and SgII appear to be involved in mechanisms of disease, such as hypertension, heart failure, and inflammatory syndromes.

The accumulated literature has brought forth novel insight notably into the oppositely directed actions of the most conspicuous peptides derived from the secreted $\mathrm{CgA}$ and SgII, namely, VS-I, Cts and SN on elements involved in combat of inflammatory insults.

VS-I and Cts by their concerted antimicrobial effects may be relevant for the first-line host-defense against invading microorganisms (Metz-Boutigue et al. 1998; 
Helle et al. 2007), while SN, seemingly devoid of antimicrobial potencies, may be regarded as an indirect contributor to innate immunity in view of its activation of chemotaxis, transendothelial extravasation, and migration of leukocytes (Fischer-Colbrie et al. 2005).

In this context, the oppositely directed effects of VS-I and $\mathrm{SN}$ on permeability of the vascular endothelium (EC) and on angiogenesis are particularly striking. Where SN appears to induce EC permeability for transendothelial transport of immunocompetent blood cells, VS-I seemingly protects the integrity of the EC barrier against the disruptive effects of pro-inflammatory agents. Wherever the released SN might trigger transendothelial passage of leukocytes including PMNs, a subsequent release of CgA-derived VS-I and Cts from the activated PMNs might serve to combat the microbial invasion. Moreover, an initial SN-induced EC leakage might in due course be reversed by the elevated plasma $\mathrm{CgA}$ and VS-I, protecting EC against further barrier disruption in response to proinflammatory cytokine.

A direct competition between VS-I and SN on regulation of EC permeability at any given time seems unlikely. Alternatively, one may anticipate a time-lag between the release of SgII and SN from sensory nerves and the increase in circulating $\mathrm{CgA}$ and VS-I in response to an inflammatory injury. Hence, the oppositely directed effects of the CgA peptide VS-I and the SgII-derived SN on EC integrity open for a new insight and understanding of the interplay between sensory nerves, PMNs, and the diffuse neuroendocrine system in inflammatory situations.

Intriguingly, VS-I and SN also appear to exert opposite effects on new formation of blood vessels. While VS-I appears to inhibit VEGF-induced cell migration, proliferation, morphogenesis, and invasion of collagen gels inherent in angiogenesis (Corti 2010), SN has, in contrast, been shown to activate EC chemotaxis, proliferation, angiogenesis, and vascularization while inhibiting EC apoptosis (Fischer-Colbrie et al. 2005), suggesting a significant role for $\mathrm{SN}$ also in tissue repair.

The accumulated evidence also provides convincing support for VS-I and Cts as regulatory peptides for the cardiovascular system, converging on alleviation of significant dysfunctions as part of several inflammatory conditions. A novel link between elevated circulating $\mathrm{CgA}$ and cardiovascular dysfunctions has been discussed in relation to potential beneficial effects of these two highly conserved CgA-derived peptides (Helle 2009, 2010a, b; Mahapatra 2008; Mahata et al. 2010). Intriguingly, $\mathrm{CgA}$ via the WE-14 domain has most recently been proposed as an autoantigen in the non-obese diabetic mouse model of type 1 diabetes (Stadinski et al. 2010).

To conclude, although the physiological impact of the secreted CgA- and SgII-derived peptides is yet to be fully understood, the accumulated evidence lends substantial support to the hypothesis that the co-stored and co-released $\mathrm{CgA}$ and $\mathrm{SgII}$ serve as prohormones for regulatory peptides with impact on a wide range of normal and pathophysiological functions, notably those related to protecting the organism against the debilitating effects of mechanical injury and inflammations.

Open Access This article is distributed under the terms of the Creative Commons Attribution Noncommercial License which permits any noncommercial use, distribution, and reproduction in any medium, provided the original author(s) and source are credited.

\section{References}

Banks P, Helle K (1965) The release of protein from the stimulated adrenal medulla. Biochem J 97:40C-41C

Blaschko H, Comline RS, Schneider FH, Silver M, Smith AD (1967) Secretion of a chromaffin granule protein, chromogranin, from the adrenal gland after splanchnic stimulation. Nature 215:58-59

Corti A (2010) Chromogranin A and the tumor microenvironment. Cell Mol Neurobiol. doi:10.1007/s10571-010-9587-8

Eiden L (1987) Is chromogranin A a prohormone? Nature 325:301

Fischer-Colbrie R, Kirschmair R, Kähler CM, Wiedermann CJ, Saria A (2005) Secretoneurin: a new player in angiogenesis and chemotaxis linking nerves, blood vessels and the immune system. Curr Protein Pept Sci 6:373-385

Helle KB (2009) Regulatory peptides from chromogranin A and secretogranin II: putative modulators of cells and tissues involved in inflammatory conditions. Regul Pept. Oct 1. [Epub ahead of print], PMID: 19800929

Helle KB (2010a) The chromogranin A-derived peptides vasostatin-I and catestatin as regulatory peptides for cardiovascular functions. Cardiovasc Res 85:9-16

Helle KB (2010b) Chromogranins A and B and secretogranin II as prohormones for regulatory peptides from the diffuse neuroendocrine system. Results Probl Cell Differ 50:21-44

Helle KB, Corti A, Metz-Boutigue M-H, Tota B (2007) The endocrine role for chromogranin A: a prohormone for peptides with regulatory properties. Cell Mol Life Sci 64:2863-2886

Mahapatra NR (2008) Catestatin is a novel endogenous peptide that regulates cardiac function and blood pressure. Cardiovasc Res 80:330-338

Mahata SK, Mahata M, Fung MM, O'Connor DT (2010) Catestatin: a multifunctional peptide from chromogranin A. Regul Pept 162:33-43

Metz-Boutigue M-H, Goumon Y, Lugardon K, Strub JM, Aunis D (1998) Antibacterial peptides are present in chromaffin cell secretory granules. Cell Mol Neurobiol 18:249-266

Penna C, Alloatti G, Gallo MP, Cerra MC, Levi R, Tullio F, Bassino E, Dolgetta S, Mahata SK, Tota B, Pagliaro P (2010) Catestatin improves post-ischemic left ventricular function and decreases ischemia/reperfusion injury in heart. Cell Mol Neurobiol. doi: 10.1007/s10571-010-9598-5

Stadinski BD, Delong T, Reisdorph N, Reisdorph R, Powell RL, Armstrong M, Piganelli JD, Barbour G, Bradley B, Crawford F, Marrack P, Mahata SK, Kappler JW, Haskins K (2010) Chromogranin $\mathrm{A}$ is an autoantigen in type 1 diabetes. Nat Immunol 11:225-231 